\title{
Many doctors pessimistic about direction of medical profession
}

\author{
n Cite as: CMAJ 2018 November 12;190:E1342. doi: 10.1503/cmaj.109-5669
}

Posted on cmajnews.com on Oct. 23, 2018.

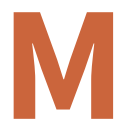
any doctors are considering quitting medicine or reducing their hours, and more feel burned out and powerless, according to recent American surveys.

Seven of 10 physicians wouldn't recommend their profession to family members, according to a national survey of more than 3400 physicians conducted by the Doctors Company, a medical malpractice insurer.

More than half of the physicians surveyed, including a third of those under age 50 , said they are considering retiring within the next five years.
Many cited electronic health records as a major cause of burnout: $54 \%$ of physicians said the tools have hurt their relationship with patients, and $61 \%$ said they hamper workflow.

Physicians also expressed frustration about how they are reimbursed, with half of those surveyed predicting that pay-forperformance models will negatively affect overall patient care.

Equally bleak were the findings of another national survey, released by the Physicians Foundation, a nonprofit grant organization for improving health care quality.

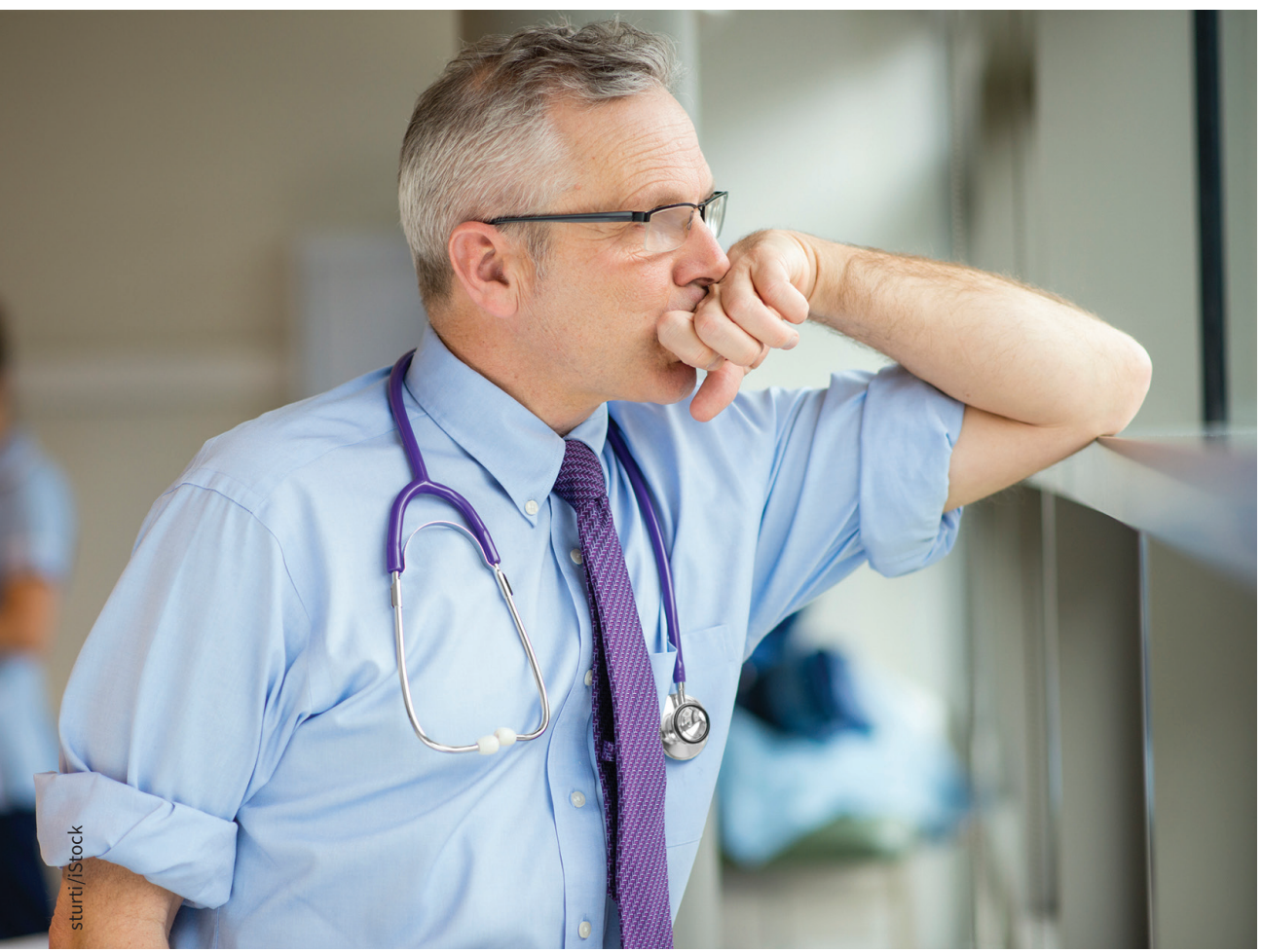

Recent American surveys suggest some dissatisfied physicians are already planning their exit from the profession.
Of the 8774 physicians surveyed, $62 \%$ said they are pessimistic about the future of medicine and 55\% describe their morale as somewhat or very negative. Four of five physicians reported working at or beyond their capacity, and about the same number said they sometimes, often or always feel burned out.

Meanwhile, a growing proportion of physicians report feeling powerless to change the health system, with $63 \%$ saying they have little or very little influence in 2018, up from 59\% in 2016.

According to the survey, "physicians are altering their practice patterns in ways likely to inhibit patient access to their services, due in part to their dissatisfaction with the prevailing medical practice environment."

About half of the doctors surveyed said they would not recommend medicine as a career to their children, and $46 \%$ plan to change career path in the next one to three years. This includes cutting hours (22\%), retiring (17\%) or finding a nonclinical position (12\%).

The survey also provides clues to doctors' discontent. Physicians cited their relationships with patients as the most satisfying part of their work, but as more American physicians are working as employees of hospitals and medical groups, they're seeing fewer patients than they would in private practice.

Once again, doctors cited electronic health records as their greatest source of professional dissatisfaction. They also reported spending nearly a quarter of their time on paperwork.

Lauren Vogel, CMAJ 